\title{
Factores predictores para el diagnóstico de la colecistitis aguda gangrenosa
}

\section{Predicting factors for the diagnosis of gangrene acute cholecystitis}

Héctor Real-Noval ${ }^{1 *}$, Jénnifer Fernández-Fernández ${ }^{2}$ y Guillermo Soler-Dorda ${ }^{1}$

'Servicio de Cirugía General y del Aparato Digestivo, Hospital de Laredo, Laredo, Cantabria; ${ }^{2}$ Servicio de Neurología, Hospital San Agustín, Avilés, Asturias. España

\section{Resumen}

Antecedentes: La colecistitis aguda gangrenosa (CG) debe tratarse precozmente por su alto riesgo de morbimortalidad. Objetivo: Identificar factores clínicos, analíticos o ecográficos que permitan diagnosticar CG preoperatoriamente. Método: Estudio de cohorte retrospectiva en el Hospital de Laredo (Cantabria, España), entre 2015 y 2017, de pacientes con diagnóstico de colecistitis aguda que hayan sido intervenidos. Se clasificó a los pacientes en dos grupos según el diagnóstico anatomopatológico: CG y colecistitis no gangrenosa (CNG). Se compararon las características demográficas, la comorbilidad, los datos analíticos y los datos ecográficos. Resultados: Fueron operados 115 pacientes, de los cuales 32 tenían CG y 83 tenían CNG. Los pacientes con CG muestran unos valores más altos de índice de neutrófilos/linfocitos $(p=0.042)$ y de proteína $C$ reactiva $(P C R)(p<0.0001)$. La colecistitis alitiásica se asoció con mas frecuencia a la $C G(24.1$ vs. $7.0 \% ; p<0.005)$. En el estudio multivariable, solo la PCR se muestra significativa. La PCR mostró un área bajo la curva ROC de 0.872, (intervalo de confianza del 95\%: 0.797-0.946). Un punto de corte de PCR de $15.25 \mathrm{mg} / \mathrm{dl}$ tuvo una alta sensibilidad (90.6\%) y un alto valor predictivo negativo (95\%). Conclusión: La PCR ayuda a identificar a los pacientes con CG para indicar una intervención quirúrgica precoz.

PALABRAS CLAVE: Colecistectomía. Colecistitis aguda gangrenosa. Ecografía. Factores pronóstico. Proteína C reactiva.

\begin{abstract}
Background: Gangrenous cholecystitis (GC) must be promptly treated for its high morbimortality. The object of our study is to identify clinical, laboratory or ultrasound factors that might us diagnose GC. Method: A Retrospective cohort study is devised including all patients admitted to Hospital de Laredo (Cantabria, Spain) between 2015 and 2017 with the diagnose of acute cholecystitis and having been operated. Patients were classified in two groups according to pathology: GC and non-GC. We compared their demographics characteristics, comorbidities, laboratory parameters and ultrasound findings. Results: Atotal of 115 patients were operated, of whom 32 had CG and 83 CNG. Neutrophil-to-lymphocyte ratio and C-reactive protein (CRP) showed significantly increased levels in GC group $(p=0.042)$ and CRP $(p<0.0001)$. To CRP showed an area under the ROC curve of 0.872 (95\% confidence interval: 0.797-0.946). Acalculous cholecystitis was significantly associated to GC (24.1 vs. $7 \% ; p<0.005)$. In the multivariate analysis only the CPR showed as a predictive factor. A cutting point of CRP at $15.25 \mathrm{mg} / \mathrm{dl}$, that had high sensibility (90.6\%) and high negative predictive value (95\%). Conclusion: CRP helped identify patients with CG to indicate early surgical intervention.
\end{abstract}

KEY WORDS: Acute gangrenous cholecystitis. Cholecystectomy. C-reactive protein. Prognostic factors. Ultrasound.

\author{
Correspondencia: \\ *Héctor Real Noval \\ Av. Luis de la Concha, 21b, $2 .^{\circ} \mathrm{b}$ \\ C.P. 39470, Renedo de Piélagos, Cantabria, España \\ E-mail: hectorrealnoval@hotmail.com
}

Fecha de recepción: 05-09-2018

Fecha de aceptación: 05-02-2019

DOI: 10.24875/CIRU.19000706
Cir Cir. 2019;87:443-449

Contents available at PubMed www.cirugiaycirujanos.com 


\section{Introducción}

La colecistitis aguda (CA) es la complicación más frecuente de la litiasis vesicular y puede ocurrir hasta en un $3 \%$ de los pacientes con colelitiasis'.

A día de hoy, ante una colecistitis aguda, el tratamiento ideal recomendado es la colecistectomía urgente durante el primer ingreso ${ }^{2}$. No obstante, hasta el $57.3 \%$ de los cirujanos españoles siguen optando por el tratamiento antibiótico y la colecistectomía diferida por diversos motivos, como puede ser la dificultad para disponer de un quirófano de urgencias o la comorbilidad del paciente'.

El tratamiento antibiótico no es factible en las colecistitis gangrenosas (CG), en las que la necrosis de la pared vesicular desemboca en la perforación de la pared, el absceso perivesicular o la peritonitis biliar ${ }^{3}$. La CG tiene una incidencia del $2-29.6 \%{ }^{4}$ y una mayor morbimortalidad ${ }^{5-7}$, por lo que es necesario identificarla precozmente. Para ello se han propuesto diversas puntuaciones clínicas, con escasa utilidad en la práctica8 ${ }^{8}$. Las pruebas de imagen, si bien son necesarias en el diagnóstico de la CA, no garantizan el diagnóstico de la $C^{9}{ }^{-10}$. Se han propuesto datos de laboratorio, como el índice de neutrófilos/linfocitos ${ }^{11,12}$ y los valores de procalcitonina ${ }^{13} y$ de proteína $C$ reactiva $(P C R)^{14,15}$.

El objetivo de este estudio es identificar factores predictores clínicos, analíticos o en pruebas de imagen, que nos permitan identificar preoperatoriamente las $C G$ para poder intervenirlas precozmente.

\section{Método}

Se llevó a cabo un estudio de cohorte retrospectiva, incluyendo todos los pacientes consecutivos ingresados con diagnóstico de CA en el Hospital Comarcal de Laredo (Cantabria, España) entre el 1 de enero de 2015 y el 31 de diciembre de 2017. Se incluyeron en el estudio aquellos casos que cumplían los siguientes criterios:

- Paciente mayor de 18 años.

- Diagnóstico de colecistitis aguda siguiendo los Criterios de Tokio de 2018'16: clínicos (signo de Murphy positivo, reacción peritoneal o masa en hipocondrio derecho), datos de inflamación (fiebre, leucocitosis $>10,000 / \mathrm{mm}^{3}$ o aumento de la $\mathrm{PCR}>3 \mathrm{mg} / \mathrm{dl}$ ) y datos compatibles con colecistitis en una prueba de imagen.

- Intervenido quirúrgicamente de forma urgente durante el primer ingreso o de forma diferida (tras un tratamiento antibiótico satisfactorio que permite dar de alta al paciente y ser operado en un segundo ingreso).

Se excluyó a los pacientes:

- Sin determinación de la PCR ni hemograma en la analítica del ingreso.

- Que hubieran sido tratados con antibioticoterapia o colecistostomía, pero que luego no fueron intervenidos quirúrgicamente.

- Con diagnóstico anatomopatológico de neoformación.

Dadas las características organizativas de nuestro hospital, el manejo inicial de las colecistitis se lleva a cabo con antibioticoterapia empírica durante 5 días basada en amoxicilina-ácido clavulánico o cefalosporinas, utilizando ciprofloxacino y metronidazol en los pacientes alérgicos a betalactámicos. Son intervenidos de urgencia aquellos pacientes que tienen una perforación o absceso vesicular, así como los que no evolucionan favorablemente en las primeras 48 horas. Se define ausencia de mejoría a las 48 horas como la presencia de fiebre, signos de reacción peritoneal e incapacidad de tolerancia a la vía oral. Durante la cirugía de urgencia, por protocolo se realiza una punción evacuadora del material biliar y se envía a cultivo; en cambio, durante la cirugía electiva no se obtiene bilis para cultivo.

Se establecen dos grupos en función de los hallazgos del estudio anatomopatológico de la pieza. Por un lado, el grupo CG, y por otro, el grupo de colecistitis no gangrenosa (CNG). Definimos la CG como aquella inflamación vesicular en la cual existen escaras de necrosis superficial o transmural en su pared, con pérdida del patrón mucoso y de la arquitectura vascular, y con un infiltrado inflamatorio de neutrófilos y células mononucleares. También se considera CG a la vesícula perforada, ya que la perforación es secundaria a la existencia de necrosis en la pared. En el grupo de CNG se incluyen los casos de colecistitis aguda, sin necrosis, intervenidos en su primer ingreso, y aquellos operados de forma diferida que cumplían los Criterios de Tokio en el primer ingreso y cuya anatomía patológica muestra datos de colecistitis aguda o crónica. Asumimos que una CA tratada médicamente puede, en el estudio anatomopatológico tras la cirugía diferida, mostrar simplemente colecistitis crónica por haber pasado ya la fase aguda. Todas las piezas fueron analizadas por el mismo patólogo. Para la clasificación en ambos grupos no se tuvo en cuenta la impresión microscópica de la existencia de 


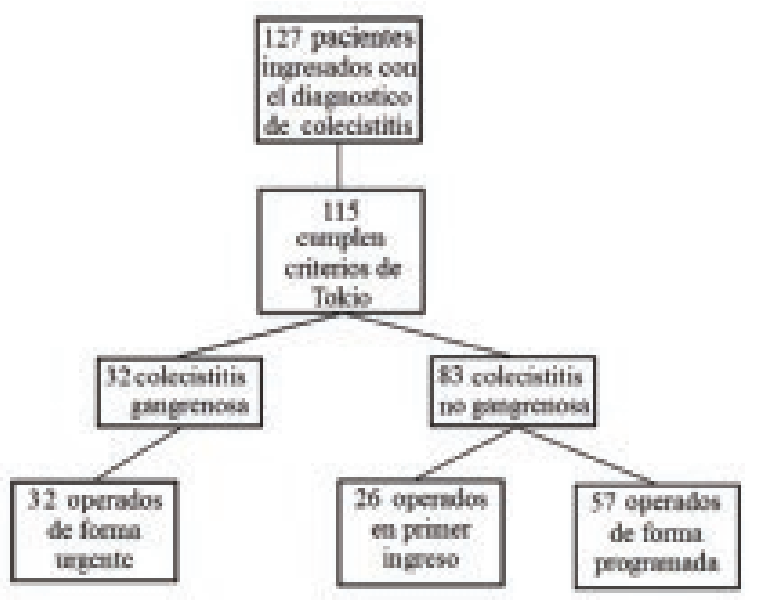

Figura 1. Distribución de los pacientes incluidos en el estudio.

necrosis por parte del cirujano durante el acto quirúrgico.

Se recogen datos referentes a las características basales del paciente (edad, sexo, diabetes mellitus, antecedentes de cardiopatía, puntuación de la American Society of Anesthesiologists [ASA], IMC e índice de Charlson), datos de la exploración (fiebre entendida como $>37,8^{\circ} \mathrm{C}$ en la sala de urgencias y reacción peritoneal en hipocondrio derecho), datos analíticos (recuento leucocitario, cociente neutrófilos/linfocitos, PCR) y datos ecográficos (Murphy ecográfico positivo, doble pared, milímetros de grosor de la pared, líquido perivesicular). Todas las ecografías han sido realizadas por radiólogos de nuestro hospital, con amplia experiencia en el campo de la radiología abdominal.

El análisis estadístico se lleva a cabo con el programa SPSS versión 15 (SPSS Inc., Chicago, IL, USA). Para evaluar la distribución normal de las variables cuantitativas se utilizan las pruebas de Shapiro-Wilks y de Komolgorov-Smirnoff. Se utilizan la pruebas de ji al cuadrado para las variables cualitativas, la t de Student para las cuantitativas con distribución normal y la prueba no paramétrica $U$ de Mann-Whitney para las cuantitativas con distribución no normal. Se establece como estadísticamente significativo cualquier resultado con $p \leq 0.05$. Para controlar posibles variables de confusión realizamos un análisis de regresión logística. Evaluamos la capacidad diagnóstica de las variables cuantitativas mediante curva ROC (Receiver Operating Characteristic).

Se han seguido los protocolos establecidos por el comité de ética del hospital para acceder a los datos de las historias clínicas con el fin de poder realizar este tipo de publicación.

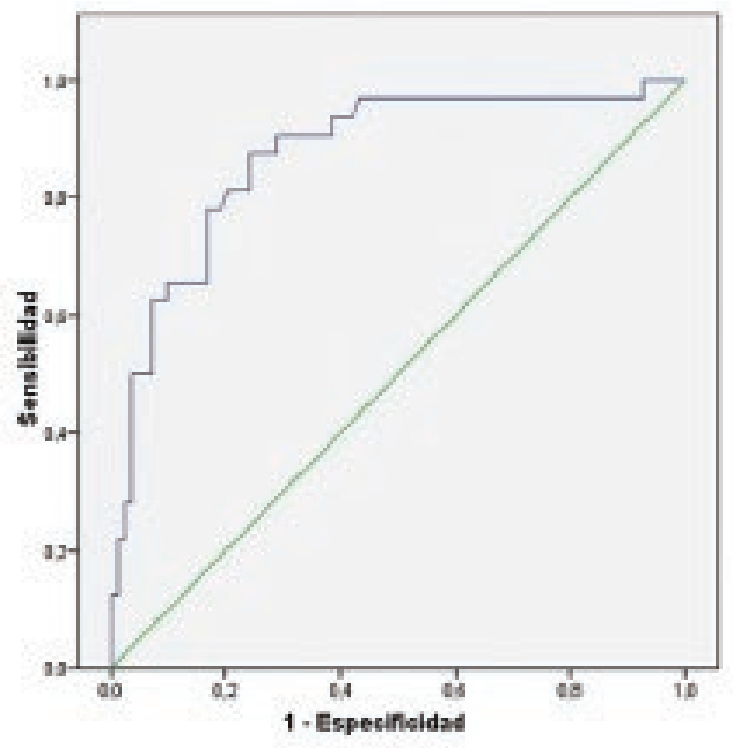

Figura 2. Curvas ROC; se corresponde con la curva ROC de la proteína $C$ reactiva.

\section{Resultados}

En el periodo del estudio ingresaron 127 pacientes con sospecha clínica de colecistitis aguda. Se excluyeron 12 pacientes que no cumplían el apartado de inflamación de los criterios de Tokio. En el resto se pudo recoger todos los datos de las variables del estudio.

Se incluyen 115 casos. El grupo de CG está constituido por 32 casos, todos intervenidos en el primer ingreso con confirmación patológica (prevalencia de CG: 28\%). El grupo CNG está formado por 83 casos (72\%), de los que fueron sometidos a intervención quirúrgica urgente 26 (31\%) y de forma programada los restantes 57 (69\%) (Fig. 1).

Analizando las características basales de ambos grupos no se encuentran diferencias estadísticamente significativas en cuanto a edad, sexo ni comorbilidad. Tampoco hay diferencias en los valores utilizando la escala Charlson ni en la presencia de fiebre. Todos los pacientes tienen reacción peritoneal en el hipocondrio derecho. En la analítica se observa que el índice de neutrófilos/linfocitos es superior en el grupo CG (mediana: 11.2) que en el grupo CNG (mediana: 10.2), con $p=0.042$. La PCR también muestra valores más elevados en el grupo CG, con una mediana de $28.5 \mathrm{mg} / \mathrm{dl}$, frente al grupo CNG, con una mediana de $9,7 \mathrm{mg} / \mathrm{dl}$ ( $p<0.0001$ ). En cuanto a las variables ecográficas analizadas, solo se observan diferencias significativas en la ausencia de litiasis (colecistitis alitiásica), que alcanza el $24.1 \%$ de las CG frente al 
Tabla 1. Datos demográficos, patología basal, datos analíticos y pruebas de imagen

\begin{tabular}{|c|c|c|c|c|c|c|}
\hline & \multicolumn{3}{|c|}{$\begin{array}{l}\text { Colecistitis no gangrenosa } \\
\qquad(\mathrm{n}=83)\end{array}$} & \multicolumn{2}{|c|}{$\begin{array}{l}\text { Colecistitis gangrenosa } \\
\qquad(n=32)\end{array}$} & $\mathrm{p}$ \\
\hline Sexo & \multicolumn{3}{|c|}{$\begin{array}{l}46 \text { hombres } \\
37 \text { mujeres }\end{array}$} & \multicolumn{2}{|c|}{$\begin{array}{l}19 \text { hombres } \\
13 \text { mujeres }\end{array}$} & $0.72^{\ddagger}$ \\
\hline Edad (años) & \multicolumn{3}{|c|}{$66 \pm 24$} & \multicolumn{2}{|c|}{$69 \pm 18$} & $0.29^{*}$ \\
\hline Diabetes & \multicolumn{3}{|c|}{16 pacientes (19\%) } & \multicolumn{2}{|c|}{10 pacientes (31\%) } & $0.17^{\ddagger}$ \\
\hline Cardiopatía isquémica & \multicolumn{3}{|c|}{3 pacientes (4\%) } & \multicolumn{2}{|c|}{2 pacientes $(6 \%)$} & $0.62^{\dagger}$ \\
\hline Índice de masa corporal & \multicolumn{3}{|c|}{$31.6 \pm 6$} & \multicolumn{2}{|c|}{$31.6 \pm 7$} & $0.6^{*}$ \\
\hline Puntuación ASA & \multicolumn{3}{|c|}{$\begin{array}{l}\text { I: } 22 \text { pacientes }(27 \%) \\
\text { II: } 59 \text { pacientes }(71 \%) \\
\text { III: } 2 \text { pacientes }(2 \%)\end{array}$} & \multicolumn{2}{|c|}{$\begin{array}{l}\text { I: } 7 \text { pacientes. }(22 \%) \\
\text { II: } 22 \text { pacientes }(69 \%) \\
\text { III: } 3 \text { pacientes }(9 \%)\end{array}$} & 0.25 \\
\hline Índice de Charlson & \multicolumn{3}{|c|}{$2.65 \pm 2.2$} & \multicolumn{2}{|c|}{$2.81 \pm 1.5$} & $0.51^{*}$ \\
\hline Fiebre & \multicolumn{3}{|c|}{3} & \multicolumn{2}{|c|}{2} & $0.39^{\dagger}$ \\
\hline Leucocitos & \multicolumn{3}{|c|}{$12,600 \pm 5300$} & \multicolumn{2}{|c|}{$14,050 \pm 6500$} & $0.065^{*}$ \\
\hline Índice neutrófilos/linfocitos & \multicolumn{3}{|c|}{$6.4 \pm 10$} & \multicolumn{2}{|c|}{$11.2 \pm 12$} & $0.042^{*}$ \\
\hline Proteína C reactiva (mg/dl) & \multicolumn{3}{|c|}{$9.7 \pm 15$} & \multicolumn{2}{|c|}{$28.5 \pm 11$} & $0.0001^{*}$ \\
\hline Alitiasis & \multicolumn{3}{|c|}{$3(4 \%)$} & \multicolumn{2}{|c|}{7 (24\%) } & $0.005^{\dagger}$ \\
\hline Doble pared & \multicolumn{3}{|c|}{$19(23 \%)$} & \multicolumn{2}{|c|}{$8(27 \%)$} & $0.15^{\ddagger}$ \\
\hline Colección perivesicular & \multicolumn{3}{|c|}{$18(22 \%)$} & \multicolumn{2}{|c|}{$10(35 \%)$} & $0.18^{\ddagger}$ \\
\hline Grosor pared (mm) & \multicolumn{3}{|c|}{$6 \pm 2$} & \multicolumn{2}{|c|}{$6 \pm 4$} & $0.25^{*}$ \\
\hline \multicolumn{7}{|c|}{$\begin{array}{l}\text { U de Mann Whitney. } \\
\text { Test exacto de Fisher. } \\
\text { fJi al cuadrado. } \\
\text { Datos expresados como mediana (intervalo intercuartil). }\end{array}$} \\
\hline & B & EE & W & Sig. & ExpB & IC $95 \%$ \\
\hline Proteína C reactiva $(\mathrm{mg} / \mathrm{dl})$ & 0.167 & 0.041 & 16.779 & 0.000 & 1.182 & $1.09-1.28$ \\
\hline Índice neutrófilos/linfocitos & 0.003 & 0.028 & 0.011 & 0.916 & 1.003 & $0.94-1.06$ \\
\hline Colecistitis alitiásica & 1.007 & 1.107 & 0.828 & 0.363 & 2.737 & $0.313-23.94$ \\
\hline
\end{tabular}

B: coeficiente de variable; EE: error estándar; ExpB: exponencial de B; IC 95\%: intervalo de confianza del 95\%; Sig: valor de p de la prueba de Wald; W: prueba de Wald.

$3.7 \%$ de las CNG, con un riesgo relativo de $6.05(p=$ 0.005) (Tabla 1).

Al realizar un análisis de regresión logística solo se muestra la PCR como factor predictor de CG (1.18; 1.09-1.28) (Tabla 2). La PCR muestra un área bajo la curva ROC de 0.872 (intervalo de confianza del $95 \%$ [IC 95\%]: 0.797-0.946) (Fig. 2).

Un valor de PCR de 15.25 tiene una sensibilidad del $90.6 \%$ y una especificidad del $69.9 \%$ para el diagnóstico de CG, así como un valor predictivo positivo (VPP) del $53 \%$ y un valor predictivo negativo del $95 \%$ (VPN) (Tablas 3 y 4).

Se obtuvo cultivo positivo en el $60 \%$ de las CNG y en el $71 \%$ de las CG, aislándose con mayor frecuencia
Escherichia coli y Klebsiella, seguidas de otras enterobacterias y enterococos.

\section{Discusión}

La CG es una forma irreversible de inflamación de la vesícula biliar. La evolución de una CA a CG constituye una indicación de cirugía urgente ${ }^{4,17}$, ya que la evolución natural del proceso no permite el manejo exclusivo con antibioticoterapia. La demora en la intervención puede ocasionar una perforación vesicular, que condiciona una sepsis grave y un shock séptico con riesgo vital. Identificar precozmente las CG permite intervenir de manera urgente a los pacientes que 
Tabla 3. Sensibilidad y especificidad para diferentes puntos de corte de los valores de la proteína $\mathrm{C}$ reactiva

\begin{tabular}{llll}
\hline $\begin{array}{l}\text { Proteína C reactiva Sensibilidad } \\
(\mathbf{m g} / \mathrm{dl})\end{array}$ & 1-especificidad & Especificidad \\
\hline 3.5000 & 0.969 & 0.771 & 0.229 \\
5.0000 & 0.969 & 0.699 & 0.331 \\
10.4800 & 0.969 & 0.470 & 0.530 \\
14.3000 & 0.906 & 0.325 & 0.675 \\
15.2500 & 0.906 & 0.301 & 0.699 \\
17.6500 & 0.875 & 0.277 & 0.723 \\
19.8500 & 0.813 & 0.241 & 0.759 \\
23.9000 & 0.688 & 0.169 & 0.831 \\
24.9500 & 0.656 & 0.096 & 0.904 \\
26.9500 & 0.625 & 0.072 & 0.928 \\
27.7500 & 0.594 & 0.072 & 0.928 \\
28.4500 & 0.500 & 0.060 & 0.940 \\
29.2000 & 0.438 & 0.036 & 0.964 \\
31.7500 & 0.375 & 0.036 & 0.964 \\
33.2000 & 0.313 & 0.036 & 0.964 \\
34.7000 & 0.219 & 0.012 & 0.988 \\
36.3500 & 0.188 & 0.012 & 0.988 \\
38.7000 & 0.0125 & 0.988 \\
\hline
\end{tabular}

tienen una $C G$ en aquellos hospitales donde por limitaciones logísticas no pueden adoptar una política de cirugía de urgencias en toda colecistitis.

Actualmente, la guía de Tokio en su versión de $2018^{16}$ constituye un documento de consenso que sirve para establecer el diagnóstico y la gravedad de las colecistitis. Sin embargo, no parece que exista una buena correlación con la gravedad antes de la intervención y los hallazgos histológicos. Así, Ambe, et al. ${ }^{18}$ encuentran que en el grupo clasificado como gravedad I (leve) en la guía de Tokio hay un $41.8 \%$ de pacientes con CG o con colecistitis necrotizante.

La prevalencia de la CG es muy variable en las distintas series. En nuestra casuística alcanza un $27.8 \%$, cifra similar a la encontrada por Borzellino, et al. ${ }^{3}$, casi seis veces superior que en la serie de Bourikian, et al. ${ }^{19}$, pero menor que el $39.8 \%$ de la serie de Fagan, et al. ${ }^{4}$. Esta variabilidad en la prevalencia puede obedecer al modo de definir la CG en los diferentes estudios. Nosotros nos hemos apoyado en el criterio anatomopatológico, pero otros estudios definen también
Tabla 4. Relación entre el punto de corte de la proteína $\mathrm{C}$ reactiva y la histología, y valores de sensibilidad, especificidad, valor predictivo positivo y valor predictivo negativo

\begin{tabular}{lccc}
\hline $\begin{array}{l}\text { Proteína C } \\
\text { reactiva }\end{array}$ & $\begin{array}{c}\text { Colecistitis no } \\
\text { gangrenosa }\end{array}$ & $\begin{array}{c}\text { Colecistitis } \\
\text { gangrenosa }\end{array}$ & Total \\
\hline$<15.25 \mathrm{mg} / \mathrm{dl}$ & 57 & 3 & 60 \\
$>15.25 \mathrm{mg} / \mathrm{dl}$ & 26 & 29 & 55 \\
Total & 83 & 32 & 115 \\
\hline Sensibilidad: $91 \%$. & & & \\
Especificidad: $70 \%$. & & \\
Valor predictivo positivo: $53 \%$. & & & \\
Valor predictivo negativ: $95 \%$. & &
\end{tabular}

como CG aquellas que macroscópicamente pudieran parecer gangrenosas durante el acto quirurgico ${ }^{14}$.

En nuestra serie, las características basales de edad, sexo, IMC, puntuación ASA, diabetes e índice de Charlson no muestran diferencias significativas. Estos resultados también son observados por otros grupos $^{3}$. Mok, et al. ${ }^{14}$ solo encuentran la edad como factor de riesgo. Varios estudios identifican la diabetes y el sexo varón como factores de riesgo $0^{6,8,19-21}$.

Diversos estudios han encontrado una asociación entre un mayor recuento de leucocitos en las CG frente a las $\mathrm{CNG}^{6,20}$. Teefey, et al. ${ }^{22}$ observan que las $\mathrm{CG}$ tienen una leucocitosis media de 13,400 leucocitos $/ \mathrm{mm}^{3}$, frente a 9400 leucocitos $/ \mathrm{mm}^{3}$ en las CNG $(p=0.01)$. La elevación de los leucocitos parece que guarda relación con el grado de inflamación ${ }^{17}$, de modo que el $58 \%$ de los pacientes con un recuento mayor de 17,000 leucocitos $/ \mathrm{mm}^{3}$ tenían una CG, frente a un $83 \%$ de pacientes con $C G$ y un recuento superior a 20,000 leucocitos $/ \mathrm{mm}^{3}$. En nuestro estudio, la mediana del recuento de leucocitos es de 12,600 en las CNG y de 14,050 en las CG, sin ser esta diferencia significativa $(p=0.065)$. Borzellino, et al. $^{3}$ tampoco encuentran asociación entre la leucocitosis y la CG.

Analizando el índice de neutrófilos/linfocitos, el valor en las CG es de 11.2 frente a 6.4 en las CNG $(p=0.042)$ en el análisis univariable, pero pierde la significación en la regresión logística. En un estudio publicado por Lee, et al. ${ }^{23}$, un mayor índice de neutrófilos/linfocitos se correlaciona con CG, enfisematosas o perforadas. Beliaev, et al. ${ }^{24}$ encuentran que el índice de neutrófilos/linfocitos es un buen marcador de inflamación para identificar las CA. En nuestro caso, el punto de corte de las CG con un valor de 11.2 es bastante superior a lo propuesto por Lee, et al. ${ }^{23}$, que es de 3 para las graves, y por Beliaev, et al. ${ }^{24}$, que es de 4.17 para las moderadas-graves.

Una PCR superior a $3 \mathrm{mg} / \mathrm{dl}$ es uno de los criterios analíticos de las guías de Tokio que definen la 
colecistitis, pero no se utiliza como marcador de gravedad $^{16}$. En nuestro estudio, el valor de la PCR en las $C G$ es casi tres veces superior al de las CNG ( 28.5 vs. $9.7 \mathrm{mg} / \mathrm{dl}$ ), lo que confiere a este reactante de fase aguda un buen poder discriminatorio. Estos datos son concordantes con estudios previos; así, Nikfarjam, et al. ${ }^{25}$ obtienen en el grupo de CG un valor de PCR de $94 \mathrm{mg} / \mathrm{dl}$, frente a $17 \mathrm{mg} / \mathrm{dl}$ en las CNG. En la serie de Mok, et al. ${ }^{14}$, la PCR en las CG tiene un valor de $331 \mathrm{mg} / \mathrm{dl}$, frente a $20.6 \mathrm{mg} / \mathrm{dl}$ en las CNG.

Otros estudios relacionan además un alto valor de la PCR con la posibilidad de conversión a cirugía abier$t^{26,27}$. El área bajo la curva ROC es de 0.872 (IC 95\%: 0.797-0.946) en el caso de la PCR, cifra bastante similar a las publicadas en otros estudios ${ }^{14,15}$. Este valor en la curva ROC nos hace considerar a la PCR un factor discriminador útil entre CG y CNG. En nuestro estudio, un punto de corte de PCR $>15.25 \mathrm{mg} / \mathrm{dl}$ permite alcanzar un equilibrio entre una alta sensibilidad, del $90.6 \%$, y una especificidad del $69.9 \%$. El VPN alcanza un valor del $95 \%$, lo que es realmente útil, ya que solo un $5 \%$ de los pacientes con cifras inferiores a 15.25 podrían tener una CG. En el estudio de Mok, et al. ${ }^{14}$, un punto de corte de $200 \mathrm{mg} / \mathrm{dl}$ tiene un VPN del 100\%.

Analizando los criterios de pruebas de imagen, se ha asociado un grosor elevado de la pared vesicular con mayor riesgo de $\mathrm{CG}^{3,8,14,22}$. Sin embargo, en nuestro caso, el grosor de la pared en ambos grupos era igual. Las colecciones líquidas perivesiculares también se han asociado a la $C^{3,4,6}$, pero en nuestra serie, aunque el grupo con CG tiene un mayor porcentaje de colecciones líquidas perivesiculares (12.5\% más), no alcanza la significación estadística. En nuestro estudio, la colecistitis alitiásica es 6,5 veces superior en el grupo CG (24.1 vs. $3.7 \%)$, pero en el análisis multivariable este dato carece de significación. Diversas series han confirmado la mayor presencia de colecistitis alitiásica en el grupo CG; así, Wu, et al. ${ }^{28}$ encuentran que 8 de 17 CG son alitiásicas, frente a 8 CNG que todas presentan litiasis. La CA alitiásica se asocia a pacientes con un estado grave y con un mayor porcentaje de CG, colecistitis perforada o abscesos perivesiculares ${ }^{29}$. Aun con las asociaciones antes descritas, las pruebas de imagen siguen siendo bastante inespecíficas para demostrar una CG; de ahí que hasta un 50\% de las CG no muestren signos en la ecografía o tengan cambios mínimos ${ }^{30}$.

Los microorganismos aislados en nuestros cultivos son similares a los reportados por la literatura previa ${ }^{31}$.

Como puntos fuertes del estudio, creemos que apoyarnos en la anatomía patológica para clasificar las
CG y las CNG es un método objetivo y verificable, que elimina la subjetividad del cirujano al clasificar macroscópicamente el grado de inflamación. De esta forma, consideramos que al eliminar la opinion subjetiva del cirujano acerca del grado de inflamación vesicular, los datos son más fiables y más reproducibles, ya que los criterios anatomopatológicos que definen una $C G$ están bien establecidos. Fitzgibbons, et al. ${ }^{32}$ ya demostraron la baja correlación entre los hallazgos intraoperatorios valorados por el cirujano y los hallazgos anatomopatológicos. Otro punto fuerte es una buena área bajo la curva con un intervalo de confianza estrecho, lo que permite identificar a la PCR como un buen elemento predictor de las CG. Como principal debilidad, se trata de un estudio retrospectivo, por lo que nuevos estudios prospectivos deberían validar nuestros datos.

En conclusión, en nuestra serie, las CG se han asociado con un valor más elevado de la PCR. La PCR se convierte en un buen elemento discriminador entre CG y CNG. Son necesarios más estudios para intentar dilucidar y elaborar una puntuación que nos permita identificar las CG con precisión, y así poder intervenirlas precozmente.

\section{Conflicto de intereses}

Se declara por parte de los autores que no existen conflictos de intereses.

\section{Financiamiento}

No hubo fuentes de financiamiento para la realización del articulo.

\section{Responsabilidades éticas}

Protección de personas y animales. Los autores declaran que para esta investigación no se han realizado experimentos en seres humanos ni en animales.

Confidencialidad de los datos. Los autores declaran que han seguido los protocolos de su centro de trabajo sobre la publicación de datos de pacientes.

Derecho a la privacidad y consentimiento informado. Los autores declaran que en este artículo no aparecen datos de pacientes.

\section{Bibliografía}

1. Badia JM, Nve E, Jimeno J, Guirao X, Figueras J, Arias-Díaz J. Tratamiento quirúrgico de la colecistitis aguda. Resultados de una encuesta a los cirujanos españoles. Cirugía Española. 2014;92:517-24. 
2. Asai K, Watanabe M, Kusachi S, Matsukiyo H, Saito T, Ishii T, et al. Evaluating the timing of laparoscopic cholecystectomy for acute cholecystitis in an experienced center based on propensity score matching. Asian J Endosc Surg. 2017;10:166-72.

3. Borzellino G, Steccanella F, Mantovani W, Genna M. Predictive factors for the diagnosis of severe acute cholecystitis in an emergency setting. Surg Endosc. 2013;27:3388-95.

4. Fagan SP, Awad SS, Rahwan K, Hira K, Aoki N, Itani KM, et al. Prognostic factors for the development of gangrenous cholecystitis. Am J Surg. 2003;186:481-5.

5. Nguyen L, Fagan SP, Lee TC, Aoki N, Itani KM, Berger DH, et al. Use of a predictive equation for diagnosis of acute gangrenous cholecystitis. Am J Surg. 2004;188:463-6.

6. Aydin C, Altaca G, Berber I, Tekin K, Kara M, Titiz I. Prognostic parameters for the prediction of acute gangrenous cholecystitis. J Hepatobiliary Pancreat Surg. 2006;13:155-9.

7. Fry DE, Cox RA, Harbrecht PJ. Gangrene of the gallbladder: a complication of acute cholecystitis. South Med J. 1981;74:666-8

8. Ambe PC, Papadakis M, Zirngibl H. A proposal for a preoperative clinical scoring system for acute cholecystitis. J Surg Res. 2016;200:473-9.

9. Yeh DD, Cropano C, Fagenholz P, King DR, Chang Y, Klein EN, et al. Gangrenous cholecystitis: deceiving ultrasounds, significant delay in surgical consult, and increased postoperative morbidity! J Trauma Acute Care Surg. 2015;79:812-6.

10. Bennett GL, Rusinek H, Lisi V, Israel GM, Krinsky GA, Slywotzky CM, et al. CT findings in acute gangrenous cholecystitis. AJR Am J Roentgenol. 2002;178:275-81.

11. Lee SK, Lee SC, Park JW, Kim S-J. The utility of the preoperative neutrophil-to-lymphocyte ratio in predicting severe cholecystitis: a retrospective cohort study. BMC Surg. 2014;14:100.

12. Beliaev AM, Angelo N, Booth M, Bergin C. Evaluation of neutrophil-to-lymphocyte ratio as a potential biomarker for acute cholecystitis. J Surg Res. 2017;209:93-101.

13. Yuzbasioglu Y, Duymaz H, Tanrikulu CS, Halhalli HC, Koc MO, Tandoğan $\mathrm{M}$, et al. Role of procalcitonin in evaluation of the severity of acute cholecystitis. Eurasian J Med. 2016;48:162-6.

14. Mok KWJ, Reddy R, Wood F, Turner P, Ward JB, Pursnani KG, et al. Is $\mathrm{C}$-reactive protein a useful adjunct in selecting patients for emergency cholecystectomy by predicting severe/gangrenous cholecystitis? Int J Surg. 2014;12:649-53.

15. Beliaev AM, Marshall RJ, Booth M. C-reactive protein has a better discriminative power than white cell count in the diagnosis of acute cholecystitis. J Surg Res. 2015;198:66-72.

16. Yokoe M, Hata J, Takada T, Strasberg SM, Asburn HJ, Wakabayashi G, et al. Tokyo Guidelines 2018. Diagnostic criteria and severity grading of acute cholecystitis (with videos). J Hepatobiliary Pancreat Sci. 2018; 25:41-54.

17. Merriam LT, Kanaan SA, Dawes LG, Angelos P, Prystowsky JB, Rege RV, et al. Gangrenous cholecystitis: analysis of risk factors and experience with laparoscopic cholecystectomy. Surgery. 1999;126:680-5; discussion 685-6.

18. Ambe PC, Christ H, Wassenberg D. Does the Tokyo guidelines predict the extent of gallbladder inflammation in patients with acute cholecystitis? A single center retrospective analysis. BMC Gastroenterol. 2015;15:142.

19. Bourikian S, Anand RJ, Aboutanos M, Wolfe LG, Ferrada P. Risk factors for acute gangrenous cholecystitis in emergency general surgery patients. Am J Surg. 2015;210:730-3.

20. Stefanidis D, Sirinek KR, Bingener J. Gallbladder perforation: risk factors and outcome. J Surg Res. 2006;131:204-8.

21. Nikfarjam M, Harnaen E, Tufail F, Muralidharan V, Fink MA, Starkey G, et al. Sex differences and outcomes of management of acute cholecystitis. Surg Laparosc Endosc Percutan Tech. 2013;23:61-5.

22. Teefey SA, Dahiya N, Middleton WD, Bajaj S, Dahiya N, Ylagan L, et al. Acute cholecystitis: do sonographic findings and WBC count predict gangrenous changes? AJR Am J Roentgenol. 2013;200:363-9.

23. Lee SK, Lee SC, Park JW, Kim SJ. The utility of the preoperative neutrophil-to-lymphocyte ratio in predicting severe cholecystitis: a retrospective cohort study. BMC Surg. 2014;14:100.

24. Beliaev AM, Angelo N, Booth M, Bergin C. Evaluation of neutrophil-to-lymphocyte ratio as a potential biomarker for acute cholecystitis. J Surg Res. 2017;209:93-101.

25. Nikfarjam $M$, Niumsawatt $V$, Sethu A, Fink MA, Muralidharan V, Starkey G, et al. Outcomes of contemporary management of gangrenous and non-gangrenous acute cholecystitis. HPB (Oxford). 2011;13:551-8.

26. Jessica Mok KW, Goh YL, Howell LE, Date RS. Is C-reactive protein the single most useful predictor of difficult laparoscopic cholecystectomy or its conversion? A pilot study. J Minim Access Surg. 2016;12:26-32.

27. Wevers KP, van Westreenen HL, Patijn GA. Laparoscopic cholecystectomy in acute cholecystitis: C-reactive protein level combined with age predicts conversion. Surg Laparosc Endosc Percutan Tech. 2013;23:163-6.

28. Wu C, Chen C, Wang C, Wong Y, Wang L, Huang C, et al. Discrimination of gangrenous from uncomplicated acute cholecystitis: accuracy of CT findings. Abdom Imaging. 2011;36:174-8.

29. Kalliafas S, Ziegler DW, Flancbaum L, Choban PS. Acute acalculous cholecystitis: incidence, risk factors, diagnosis, and outcome. Am Surg. 1998;64:471-5.

30. Yeh D, Cropano C, Fagenholz P, King D, Chang Y, Klein E, et al. Gangrenous cholecystitis: deceiving ultrasounds, significant delay in surgical consult, and increased postoperative morbidity. J Trauma Acute Care Surg. 2015;79:812-6.

31. Csendes A, Burdiles P, Maluenda F, Diaz JC, Csendes P, Mitru N. Simultaneous bacteriologic assessment of bile from gallbladder and common bile duct in control subjects and patients with gallstones and common duct stones. Arch Surg. 1996;131:389.

32. Fitzgibbons RJ Jr, Tseng A, Wang H, Ryberg A, Nguyen N, Sims KL. Acute cholecystitis. Does the clinical diagnosis correlate with the pathological diagnosis? Surg Endosc. 1996;10:1180-4. 